\title{
Comparative evaluation of anthropometric measures to predict cardiovascular risk factors in Tehranian adult women
}

\author{
Ahmad Esmaillzadeh, Parvin Mirmiran and Fereidoun Azizi* \\ Endocrine Research Center, Shaheed Beheshti University of Medical Sciences, PO Box 19395-4763, Tehran, \\ Islamic Republic of Iran
}

Submitted 21 December 2004: Accepted 14 June 2005

\begin{abstract}
Objective: To compare the ability of waist circumference (WC), body mass index (BMI), waist-to-hip ratio (WHR) and waist-to-height ratio (WHtR) to predict cardiovascular risk factors in an urban adult population of Tehranian women.

Design: Population-based cross-sectional study.

Setting: Tehran, the capital of Iran.

Subjects: This study was conducted on 5073 women aged 18-74 years, participants of the Tehran Lipid and Glucose Study. Demographic data were collected. Anthropometric indices were measured according to standard protocols. Cut-off points of BMI, WC, WHR and WHtR were considered as $25 \mathrm{~kg} \mathrm{~m}^{-2}, 80 \mathrm{~cm}, 0.8$ and 0.5 , respectively. Blood pressure was measured and hypertension was defined based on the sixth report of the Joint National Committee on Prevention, Detection, Evaluation and Treatment of High Blood Pressure. Biochemical analyses were conducted on fasting blood samples. Diabetes was defined as fasting plasma glucose $\geq 126 \mathrm{mg} \mathrm{dl}^{-1}$ or 2-hour plasma glucose $\geq 200 \mathrm{mg} \mathrm{dl}^{-1}$ and dyslipidaemia based on the third report of the National Cholesterol Education Program Expert Panel. The presence of 'at least one risk factor' from the three major cardiovascular risk factors (hypertension, dyslipidaemia and diabetes) was also evaluated.

Results: Mean ( \pm standard deviation) age of women was $39.9 \pm 14.6$ years; mean BMI, WC, WHR and WHtR were $27.1 \pm 1.5 \mathrm{~kg} \mathrm{~m}^{-2}, 86.5 \pm 13.5 \mathrm{~cm}$ and $0.83 \pm 0.08$ and $0.55 \pm 0.08$, respectively. Of the four anthropometric measures, WC had the highest sensitivity and specificity to identify subjects with risk factors in both the 18-39 year and the 40-74 year age categories. WC was seen to have a higher percentage of correct prediction than BMI, WHR and WHtR.

Conclusion: It is concluded that WC is the best screening measure for cardiovascular risk factors, compared with BMI, WHR and WHtR, in Tehranian adult women.
\end{abstract}

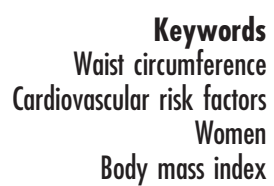

Body mass index
The prevalence of obesity has increased dramatically in industrialised and developing countries ${ }^{1-3}$, such that World Health Organization (WHO) has reported overweight and obesity to be an escalating worldwide epidemic $^{4}$. Obese people are susceptible to other chronic disease such as diabetes, cardiovascular disease (CVD) and some cancers ${ }^{4}$. In Iran, the prevalence of both obesity and CVD risk factors is high ${ }^{5,6}$.

Although body mass index (BMI) as an index of obesity recommended by $\mathrm{WHO}^{7}$ is related to disease risk $^{8}$, some studies suggest that the pattern of body fat distribution is a more important determinant of disease risk ${ }^{9-11}$ and individuals with a high proportion of abdominal fat have higher risks for developing diabetes ${ }^{9}$, hypertension ${ }^{12}$ and $\mathrm{CVD}^{13}$. Unfortunately, there is no standard measure of abdominal obesity that is widely accepted. Although the majority of studies have found waist circumference (WC) to be a better indicator of abdominal obesity and a better predictor of CVD than either BMI or waist-to-hip ratio (WHR) ${ }^{14-17}$, such a finding has not been confirmed in Asian countries ${ }^{18}$ and the best index of obesity that is predictive for CVD risk still remains controversial. On the other hand, most studies examining the risk of adverse health associated with obesity have been based on data from Europe or the USA, and few data are available from the Asia-Pacific region. The importance of this point is reinforced when we note that the predictive power of anthropometric indices is population-dependent ${ }^{19}$ and varies from race to race $^{20}$. It is essential, therefore, to identify the best simple anthropometric index to predict chronic disease risk in each population, to facilitate enhanced screening for disease risk. The present study was designed to compare the ability of WC, BMI, WHR and waist-to-height ratio (WHtR) to predict cardiovascular risk factors in an urban adult population of Tehranian women. 


\section{Subjects and methods}

\section{Subjects}

This study was conducted within the framework of the Tehran Lipid and Glucose Study (TLGS), a prospective study performed on a representative sample of residents of District 13 of Tehran with the aim of determining the prevalence of non-communicable disease risk factors and developing a healthy lifestyle to curtail these risk factors ${ }^{21}$. In the TLGS, 15005 people aged 3 years and over living in District 13 of Tehran were selected by a multistage cluster random sampling method, among whom were 10837 people (6294 females) aged 18-74 years. In the present population-based cross-sectional study, 5073 females who had full relevant data and did not use pharmacological treatment for their diabetes or dyslipidaemia were included. There was no significant difference in any of the main parameters of the study between those included and those excluded. This study was approved by the research council of the Endocrine Research Center, Shaheed Beheshti University of Medical Sciences and informed written consent was obtained from each subject.

\section{Methods}

Subjects were interviewed privately, in face-to-face interviews conducted by trained interviewers using pre-tested questionnaires. Initially, information on age, smoking habits, physical activity and educational level was collected using validated questionnaires, as reported earlier $^{22-24}$. With regard to smoking habits, subjects were categorised as daily smokers, ex-smokers, occasional smokers and non-smokers. Data on physical activity were obtained using the Lipid Research Clinic (LRC) questionnaire. This questionnaire is a simple and comprehensible measure including four questions; no special education is needed to complete this questionnaire. Subjects were classified as having light, moderate or severe physical activity based on their oral responses to the questionnaire according to LRC guidelines. Education level of subjects was scored as follows: illiterate $=0$, Nehzat (persons able to read and write) $=2$, elementary school $=5, \quad$ guidance $\quad$ school $=9, \quad$ high school graduate $=12$, intermediate $=14$, bachelor $=16$, master and postgraduate $=18$ and specialist $=20$. Based on the educational level scoring, subjects were grouped as low $(<5)$, moderate (6-12) and highly educated $(>12)$ persons. Weight was measured, while the subjects were minimally clothed and without shoes, using digital scales and recorded to the nearest $100 \mathrm{~g}$. Height was measured in the standing position, without shoes, using a measuring tape while the shoulders were in a normal state. BMI was calculated as weight in kilograms divided by the square of height in metres. WC was measured at the narrowest level and hip circumference was measured at the maximal level over light clothing, using a non-stretchable measuring tape, without any pressure to the body surface, and both were recorded to the nearest $0.1 \mathrm{~cm}$. As the measurements were taken over light clothing, participants were asked to remove tight or loose garments and belts intended to alter the shape of the body, and the person performing the measurement inspected the tension of the tape on the subject's body to ensure that it had the proper tension (not too loose or too tight). The narrowest waist is easy to identify in most subjects. However, for some subjects there is no single narrowest waist because of either a large amount of abdominal fat or extreme thinness ${ }^{25}$. In the present study, when the narrowest point of waist was difficult to identify (particularly in obese subjects), we measured waist circumference immediately below the end of the lowest rib, because in most subjects the narrowest waist is at the lowest rib $^{25}$. WHR was calculated as WC divided by hip circumference, and WHtR as WC divided by height. To reduce subjective error all measurements were taken by the same person.

To evaluate blood pressure participants were initially made to rest for $15 \mathrm{~min}$. Then a qualified physician measured blood pressure two times during physical examinations in a seated position after one initial measurement for determining peak inflation level using a standard mercury sphygmomanometer. On the basis of the circumference of the participant's arm, a regular adult or large cuff was chosen. The cuff was placed on the participant's right arm, at the heart level, and inflated at as high an increment rate as possible, until the cuff pressure was $30 \mathrm{mmHg}$ above the level at which the radial pulse disappeared. There was an interval of at least $30 \mathrm{~s}$ between these two separate measurements, and thereafter the mean of the two measurements was considered as the participant's blood pressure. The systolic blood pressure was defined as the appearance of the first sound (Korotkoff phase 1) and diastolic blood pressure was defined as the disappearance of the sound (Korotkoff phase 5) during deflation of the cuff at a $2-3 \mathrm{mms}^{-1}$ decrement rate of the mercury column. Before measuring blood pressure the participant was questioned about drinking tea or coffee, physical activity, smoking and full bladder.

For each study participant, a blood sample was drawn into a Vacutainer tube between 07.00 and 09.00 hours after $12-14 \mathrm{~h}$ overnight fasting. Blood samples were taken in a sitting position according to the standard protocol and centrifuged within 30-45 min of collection. All blood lipid analyses were done at the TLGS research laboratory on the day of blood collection. The analysis of samples was performed using a Selectra 2 auto-analyser (Vital Scientific, Spankeren, The Netherlands). A 75-g oral glucose tolerance test was administered and plasma glucose concentration was measured $2 \mathrm{~h}$ post-challenge (2-h PG). Fasting plasma glucose (FPG) was measured on the day of blood collection by an enzymatic colorimetric method using glucose oxidase. Total cholesterol (TC) and triglycerides (TG) were assayed by enzymatic colorimetric 
tests with cholesterol esterase and cholesterol oxidase and glycerol phosphate oxidase, respectively, using kits from Pars Azmoon Inc. (Iran). High-density lipoprotein cholesterol (HDL-C) was measured after precipitation of the apolipoprotein B-containing lipoproteins with phosphotungstic acid. Low-density lipoprotein cholesterol (LDL-C) was calculated from serum TC, TG and HDL-C using the Friedewald formula ${ }^{26}$. It was not calculated when TG concentration was greater than $400 \mathrm{mg} \mathrm{dl}^{-1}$. Assay performance was monitored once every 20 tests interval using the lipid control serum, 'Percinorm' (normal range) or 'Percipath' (pathologic range) as applicable (catalogue no. 1446070 and 171778, respectively; Boehringer Mannheim, Germany). Lipid standard (CFAS, catalogue no. 759350; Boehringer Mannheim) was used to calibrate the Selectra 2 auto-analyser for each day of laboratory analyses. All samples were analysed when internal quality control met the acceptance criteria. Interand intra-assay coefficients of variation were 2.0 and $0.5 \%$ for TC and 1.6 and $0.6 \%$ for TG, respectively.

\section{Definition of terms}

Cut-off points used for BMI, WHR, WHtR and WC were $25 \mathrm{~kg} \mathrm{~m}^{-2}, 0.8,0.5$ and $80 \mathrm{~cm}$, respectively ${ }^{7,16}$. Dyslipidaemia was defined based on the third report of the National Cholesterol Education Program Expert Panel $^{27}$ as TC $\geq 240 \mathrm{mg} \mathrm{dl}^{-1}$ or LDL-C $\geq 160 \mathrm{mg} \mathrm{dl}^{-1}$ or HDL-C $<40 \mathrm{mg} \mathrm{dl}^{-1}$ or serum TG $\geq 200 \mathrm{mg} \mathrm{dl}^{-1}$. Hypertension was defined as systolic blood pressure $\geq 140 \mathrm{mmHg}$ or diastolic blood pressure $\geq 90 \mathrm{mmHg}$ or current use of antihypertensive medication based on the sixth report of the Joint National Committee on Prevention, Detection, Evaluation and Treatment of High Blood Pressure ${ }^{28}$. Diabetes mellitus was defined ${ }^{29}$ as FPG $\geq 126 \mathrm{mg} \mathrm{dl}^{-1}$ or 2 -h PG $\geq 200 \mathrm{mg} \mathrm{dl}^{-1}$. The presence of 'at least one risk factor' of the three major risk factors for CVD (hypertension, dyslipidaemia and diabetes) was also evaluated.

\section{Statistical methods}

All data were analysed using SPSS version 9.09 (SPSS Inc., Chicago, IL, USA). Subjects were divided into two age categories: 18-39 and 40-74 years. We used histogram and $\mathrm{P}-\mathrm{P}$ plots to determine whether the variables were normally distributed. Because all variables had a normal distribution in our population, we used parametric tests in our analysis. Comparison of age, anthropometric indicators, biochemical indices and blood pressure in these two age categories was performed using Student's $t$-test. In order to overcome the possible bias associated with the use of cut-off values, linear regressions were performed by using risk factors as the dependent variables, and age and each of the anthropometric measures as the independent variables, in separate models. All anthropometric measures were not included simultaneously in these models to avoid collinearity that these independent variables may have. Logistic regression was used for each risk factor to determine the associations between obesity indicators and CVD risk factors. An odds ratio with a 95\% confidence interval that did not include the value of 1.0 in its range was considered statistically significant. All anthropometric measures were included simultaneously in these models and confounding variables such as age (years), physical activity (light, moderate, severe), smoking (daily smokers, ex-smokers, occasional smokers and non-smokers) and educational level (low, moderate, high) were considered as covariates. McNemar's chi-square statistic was used to determine whether significant differences were present between any two of the four anthropometric measures in terms of accuracy in classifying individuals according to the presence/absence of risk factors.

\section{Results}

Mean ( \pm standard deviation (SD)) age of the women was $39.9 \pm 14.6$ years. Mean $( \pm \mathrm{SD}) \mathrm{BMI}$ and WC were $27.1 \pm 1.5 \mathrm{~kg} \mathrm{~m}^{-2}$ and $86.5 \pm 13.5 \mathrm{~cm}$, and mean $( \pm \mathrm{SD})$ WHR and WHtR were $0.83 \pm 0.08$ and $0.55 \pm 0.08$, respectively. All anthropometric measures were higher for the 40-74 year age category than for the 18-39 year age group. Older subjects (40-74 years) had higher blood pressure and lipid profiles than the 18-39-year-olds, except for HDL-C level, which was similar in both age categories (Table 1).

Prevalence of cardiovascular risk factors and the proportion of women who had abnormal BMI, WC, WHR and WHtR are presented in Fig. 1. Hypertension and diabetes were seen in $22 \%$ and $7 \%$ of subjects, respectively. The prevalence of dyslipidaemia and 'at least one risk factor' was $64 \%$ and $68 \%$, respectively. Sixtyfive per cent of subjects had BMI $\geq 25 \mathrm{~kg} \mathrm{~m}^{-2}$ and $69 \%$ had $\mathrm{WC} \geq 80 \mathrm{~cm}$. The proportion of women with WHR $\geq 0.8$ and WHtR $\geq 0.5$ was $64 \%$ and $63 \%$, respectively. Cardiovascular risk factors were more prevalent in the 40-74 year age category than in the 18-39 year age category in all cases.

The results of entering anthropometric measures in regression models when predicting cardiovascular risk factors after adjustment for age are shown in Table 2. All anthropometric indicators contributed to various cardiovascular risk factors. The associations were negative for HDL-C and positive for the other risk factors.

Multivariate-adjusted odds ratios for the presence of cardiovascular risk factors according to anthropometric measures are presented in Table 3. After controlling for potential confounding variables, subjects with abnormal anthropometric measures had higher odds for having cardiovascular risk factors. However, the association between WHR and hypertension, BMI and diabetes, WHtR and diabetes, WHtR and dyslipidaemia, and WHtR and at least one risk factor, was not significant. 
(a)

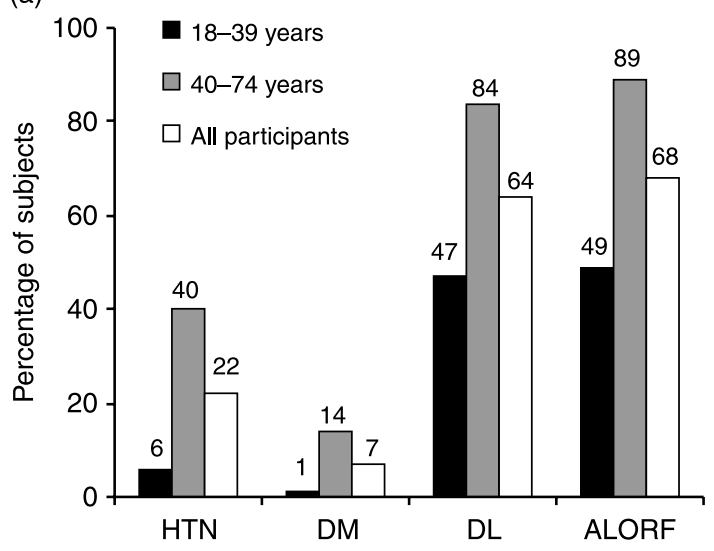

(b)

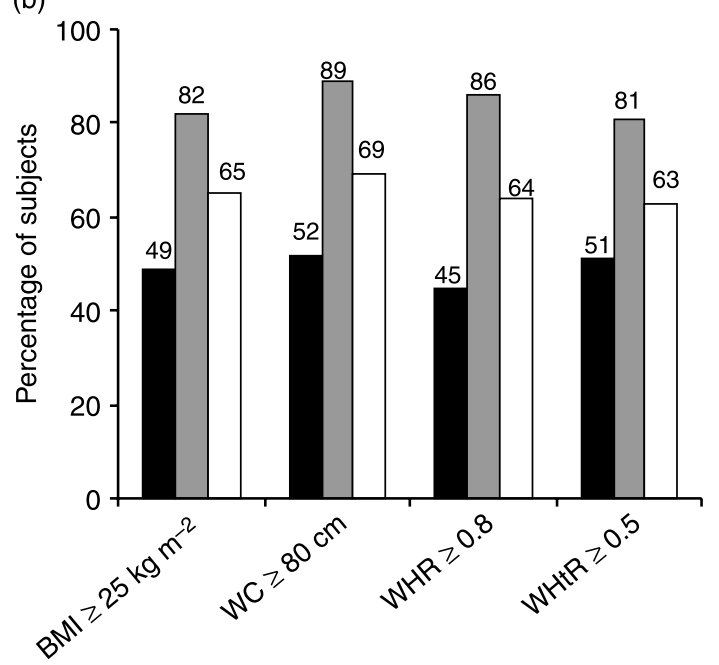

Fig. 1 (a) Prevalence of risk factors for cardiovascular disease (HTN - hypertension; DM - diabetes; DL - dyslipidaemia; ALORF - at least one risk factor) and (b) the proportion of women who had abnormal body mass index (BMI), waist circumference (WC), waist-to-hip ratio (WHR) and waist-to-height ratio (WHtR). Hypertension and diabetes were seen in $22 \%$ and $7 \%$ of subjects, respectively. The prevalence of dyslipidaemia and 'at least one risk factor' was $64 \%$ and $68 \%$, respectively. Sixty-five per cent of subjects had BMI $\geq 25 \mathrm{~kg} \mathrm{~m}^{-2}$ and $69 \%$ had WC $\geq 80 \mathrm{~cm}$. The proportion of women with $\mathrm{WHR} \geq 0.8$ and $\mathrm{WHtR}$ $\geq 0.5$ was $64 \%$ and $63 \%$, respectively. Cardiovascular risk factors were more prevalent in the $40-74$ year age category than in the 18-39 year age category in all cases

A comparison of sensitivity and specificity of the four anthropometric indicators is presented in Table 4. Of the four indicators, WC had the highest sensitivity and specificity in the two age categories of 18-39 years and 40-74 years as well as for all subjects combined, except for dyslipidaemia in all subjects where BMI and WHR had higher specificity than WC. WC also had the highest sensitivity and specificity for diabetes and 'at least one risk factor'. Sensitivity of the anthropometric indicators' cut-off points increased and specificity decreased with age from the 18-39 year age category to the 40-74 year age category for all risk factors.

Comparison of anthropometric measures with respect to their ability to predict the presence/absence of 'at least one risk factor' is shown in Table 5. Because the same results were obtained for both age categories of 18-39 and 40-74 years, we present findings only for all subjects combined. Cut-off points of WC are seen to have a higher percentage of correct prediction than BMI, WHR and WHtR. There was a significant difference between the percentage of individuals whose risk factor status was correctly predicted using WC (but not so using BMI) and the percentage of individuals whose risk factor status was correctly predicted using BMI (but not so using WC) $(P<0.001)$. Similarly, significant differences were seen between WC and WHR $(P<0.001)$ and also between WC and WHtR $(P<0.01)$ and between WHR and WHtR $(P<0.001)$. The findings for the other risk factors investigated (data not shown) were the same as those for 'at least one risk factor'.

\section{Discussion}

This is the first study that has attempted to comparatively evaluate WC, BMI, WHR and WHtR as indicators of cardiovascular risk factors in an urban adult population of Tehranian women. The findings showed WC to be the best anthropometric measure to use in identifying individuals with risk factors for CVD. This was reflected in the comparison of the accuracy of the cut-off points in risk factor prediction.

WC has been recognised as a good measure of abdominal fat and particularly the more metabolically active intra-abdominal fat ${ }^{15,30}$. The deposition of abdominal visceral adipose tissue is associated with an increase in portal free fatty acid concentration, which leads to plasma disturbances such as hyperinsulinaemia ${ }^{15,31}$, which could be the basis for other cardiovascular risk factors ${ }^{32}$.

The findings of the present study concur with previous studies in concluding that WC is probably the best single anthropometric measure to use in identifying individuals with cardiovascular risk factors. In a cross-sectional study conducted on 9019 participants (including 4631 women) of the Third National Health and Nutrition Examination Survey (NHANES III), Zhu et ll $^{33}$ showed that WC measured in the horizontal plane at a point marked just above the right ilium on the midaxillary line - is more closely linked to CVD risk factors than is BMI in both men and women. The same result has been reported from China in a cross-sectional study on postmenopausal Chinese women ${ }^{34}$. Dobbelsteyn et al. $^{16}$ showed in the Canadian Heart Health Survey that WC - measured at the level of noticeable waist narrowing - has more accuracy than BMI and WHR to predict CVD risk factors in men and women. Other investigators also reported such findings exclusively in women ${ }^{17,35,36}$, whereas WHtR in some communities ${ }^{37,38}$ and WHR in others ${ }^{39,40}$ have been suggested as better screening measures for cardiovascular risk factors. Different sites for waist measurement ${ }^{41}$, racial differences between different 
Table 1 Age, anthropometric indicators, biochemical indices and blood pressure in Tehranian women, Tehran Lipid and Glucose Study

\begin{tabular}{|c|c|c|c|}
\hline \multirow[b]{2}{*}{ Variable } & \multicolumn{2}{|c|}{ Age group } & \multirow[b]{2}{*}{ All participants $(n=5073)$} \\
\hline & $18-39$ years $(n=2734)$ & $40-74$ years $(n=2339)$ & \\
\hline Age (years) & $28.3 \pm 6.4(18-39)^{*}$ & $53.1 \pm 8.9(40-74) \dagger$ & $39.9 \pm 14.6(18-74)$ \\
\hline BMI $\left(\mathrm{kg} \mathrm{m}^{-2}\right)$ & $25.3 \pm 4.8(17-46)$ & $29.2 \pm 4.6(18-46) \dagger$ & $27.1 \pm 5.1(17-46)$ \\
\hline WC $(\mathrm{cm})$ & $80.6 \pm 11.6(52-131)$ & $93.4 \pm 11.3(61-146) \dagger$ & $86.5 \pm 13.1(52-146)$ \\
\hline WHR & $0.79 \pm 0.07(0.57-1.07)$ & $0.88 \pm 0.07(0.59-1.18) \dagger$ & $0.83 \pm 0.08(0.57-1.18)$ \\
\hline WHtR & $0.50 \pm 0.07(0.30-0.79)$ & $0.60 \pm 0.07(0.37-0.86) \dagger$ & $0.55 \pm 0.08(0.30-0.86)$ \\
\hline Total cholesterol $\left(\mathrm{mg} \mathrm{dl}^{-1}\right)$ & $187 \pm 63(87-419)$ & $232 \pm 46(100-389) \dagger$ & $208 \pm 47(87-419)$ \\
\hline Serum triglycerides $\left(\mathrm{mg} \mathrm{dl}^{-1}\right)$ & $118 \pm 37(80-393)$ & $178 \pm 77(63-385) \dagger$ & $146 \pm 76(63-393)$ \\
\hline $\mathrm{HDL}-\mathrm{C}\left(\mathrm{mg} \mathrm{dl}^{-1}\right)$ & $45 \pm 11(18-93)$ & $45 \pm 11(20-110) \dagger$ & $45 \pm 11(18-110)$ \\
\hline LDL-C $\left(\mathrm{mg} \mathrm{dl}^{-1}\right)$ & $118 \pm 33(76-335)$ & $151 \pm 40(56-326) \dagger$ & $133 \pm 40(56-335)$ \\
\hline Plasma glucose $\left(\mathrm{mg} \mathrm{dl}^{-1}\right)$ & $88 \pm 15(65-214)$ & $107 \pm 43(61-323) \dagger$ & $97 \pm 33(61-323)$ \\
\hline Systolic blood pressure (mmHg) & $109 \pm 11(71-163)$ & $128 \pm 22(83-198) \dagger$ & $118 \pm 19(71-198)$ \\
\hline Diastolic blood pressure $(\mathrm{mmHg})$ & $74 \pm 9(68-119)$ & $81 \pm 11(60-131) \dagger$ & $77 \pm 11(60-131)$ \\
\hline
\end{tabular}

BMI - body mass index; WC - waist circumference; WHR - waist-to-hip ratio; WHtR - waist-to-height ratio; HDL-C - high-density lipoprotein cholesterol; LDL-C - low-density lipoprotein cholesterol.

* Data are presented as mean \pm standard deviation with range in parentheses.

† Significant difference compared with the age category of $18-39$ years (Student's $t$-test): $P<0.01$.

Table 2 Contributions of anthropometric measures to cardiovascular disease risk factors in Tehranian adult women; Tehran Lipid and Glucose Study

\begin{tabular}{|c|c|c|c|c|}
\hline Variable & BMI & WC & WHR & $\mathrm{WHtR}$ \\
\hline FPG & $0.248 \pm 0.087^{*}$ & $0.279 \pm 0.037$ & $0.217 \pm 0.051$ & $0.245 \pm 0.057$ \\
\hline TC & $0.583 \pm 0.046$ & $1.46 \pm 0.108$ & $0.543 \pm 0.072$ & $0.981 \pm 0.071$ \\
\hline TG & $2.72 \pm 0.121$ & $3.69 \pm 0.186$ & $2.23 \pm 0.123$ & $2.72 \pm 0.121$ \\
\hline HDL-C & $-0.229 \pm 0.030$ & $-0.309 \pm 0.013$ & $-0.241 \pm 0.019$ & $-0.161 \pm 0.020$ \\
\hline LDL-C & $0.666 \pm 0.064$ & $1.03 \pm 0.097$ & $0.338 \pm 0.064$ & $0.397 \pm 0.041$ \\
\hline SBP & $0.404 \pm 0.029$ & $0.606 \pm 0.044$ & $0.265 \pm 0.029$ & $0.249 \pm 0.019$ \\
\hline DBP & $0.344 \pm 0.017$ & $0.617 \pm 0.026$ & $0.164 \pm 0.080$ & $0.223 \pm 0.011$ \\
\hline
\end{tabular}

BMI - body mass index; WC - waist circumference; WHR - waist-to-hip ratio; WHtR - waist-to-height ratio; FPG - fasting plasma glucose; TC - total cholesterol; TG - triglycerides; HDL-C - high-density lipoprotein cholesterol; LDL-C - low-density lipoprotein cholesterol; SBP - systolic blood pressure; DBP - diastolic blood pressure.

${ }^{*}$ Data are presented as $\beta \pm$ standard error of the mean. All values are significant at $P<0.05$.

Table 3 Multivariate-adjusted odds ratios for the presence of cardiovascular disease risk factors according to anthropometric measures in Tehranian adult women; Tehran Lipid and Glucose Study

\begin{tabular}{llccc}
\hline Variable & Hypertension* & \multicolumn{1}{c}{ Diabetes* $^{*}$} & Dyslipidaemia* & At least one risk factor† \\
\hline $\mathrm{BMI} \geq 25 \mathrm{~kg} \mathrm{~m}^{-2}$ & $1.6(1.3-2.0) \ddagger$ & $0.8(0.6-1.3)$ & $1.5(1.2-1.9)$ & $1.7(1.3-2.0)$ \\
$\mathrm{BMI} \geq 30 \mathrm{~kg} \mathrm{~m}^{-2}$ & $2.0(1.7-2.3)$ & $1.1(0.9-1.4)$ & $1.9(1.6-2.6)$ & $2.3(1.9-2.8)$ \\
$\mathrm{WC} \geq 80 \mathrm{~cm}$ & $2.2(1.5-2.9)$ & $2.7(1.8-3.4)$ & $1.9(1.6-2.4)$ & $1.9(1.4-2.3)$ \\
WHR $\geq 0.8$ & $1.1(0.90-1.6)$ & $2.1(1.2-4.0)$ & $1.2(1.0-1.6)$ & $1.3(1.0-1.5)$ \\
WHtR $\geq 0.5$ & $1.7(1.1-2.6)$ & $1.2(0.5-2.5)$ & $1.2(0.8-1.6)$ & $1.2(0.7-1.4)$ \\
\hline
\end{tabular}

BMI - body mass index; WC - waist circumference; WHR - waist-to-hip ratio; WHtR - waist-to-height ratio.

* Hypertension was defined as systolic blood pressure $\geq 140 \mathrm{mmHg}$ or diastolic blood pressure $\geq 90 \mathrm{mmHg}$ or current use of antihypertensive medication; diabetes was defined as fasting plasma glucose $\geq 126 \mathrm{mg} \mathrm{dl}^{-1}$ or 2-hour plasma glucose $\geq 200 \mathrm{mgdl} \mathrm{di}^{-1}$ dyslipidaemia was considered as having total cholesterol $\geq 240 \mathrm{mg} \mathrm{dl}^{-1}$ or triglycerides $\geq 200 \mathrm{mg} \mathrm{dl}^{-1}$ or high-density lipoprotein cholesterol $<40 \mathrm{mg} \mathrm{dl}^{-1}$ or low-density lipoprotein cholesterol $\geq 160 \mathrm{mg} \mathrm{dl}^{-1}$.

$\dagger$ Risk factors include hypertension, diabetes and dyslipidaemia.

¥Data are presented as odds ratio adjusted for age, physical activity, smoking, education level and mutual effects of anthropometric measures, with $95 \%$ confidence interval in parentheses.

communities $^{42}$ and differences in the BMI and age range ${ }^{43}$ of subjects studied could lead to different findings. Using different cut-off points of anthropometric measures and different definitions for cardiovascular risk factors could also be the origin of discrepancy in findings.
The WC measure has several advantages over other anthropometric indicators. Of primary importance is the simplicity with which it may be used in a clinical setting and the ease of interpretation. It requires only the use of a tape measure, alleviating the expense of the equipment 
Table 4 Sensitivity and specificity of anthropometric measures to predict cardiovascular disease risk factors in Tehranian adult women; Tehran Lipid and Glucose Study

\begin{tabular}{|c|c|c|c|c|c|c|c|c|}
\hline \multirow[b]{2}{*}{ Variable } & \multicolumn{2}{|c|}{ Hypertension* } & \multicolumn{2}{|c|}{ Diabetes ${ }^{*}$} & \multicolumn{2}{|c|}{ Dyslipidemia* } & \multicolumn{2}{|c|}{ At least one risk factor† } \\
\hline & Sensitivity & Specificity & Sensitivity & Specificity & Sensitivity & Specificity & Sensitivity & Specificity \\
\hline \multicolumn{9}{|l|}{$18-39$ years } \\
\hline $\mathrm{BMI} \geq 25 \mathrm{~kg} \mathrm{~m}^{-2}$ & 83 & 53 & 84 & 51 & 65 & 65 & 62 & 60 \\
\hline$W C \geq 80 \mathrm{~cm}$ & 89 & 58 & 90 & 58 & 73 & 68 & 68 & 68 \\
\hline WHR $\geq 0.8$ & 68 & 56 & 86 & 53 & 58 & 66 & 55 & 65 \\
\hline $\mathrm{WH} \mathrm{tR} \geq 0.5$ & 84 & 50 & 84 & 50 & 68 & 60 & 64 & 64 \\
\hline \multicolumn{9}{|l|}{$40-74$ years } \\
\hline $\mathrm{BMI} \geq 25 \mathrm{~kg} \mathrm{~m}^{-2}$ & 86 & 22 & 82 & 25 & 84 & 26 & 83 & 29 \\
\hline$W C \geq 80 \mathrm{~cm}$ & 95 & 28 & 97 & 33 & 96 & 28 & 92 & 35 \\
\hline$W H R \geq 0.8$ & 90 & 20 & 90 & 18 & 87 & 23 & 86 & 30 \\
\hline WHtR $\geq 0.5$ & 91 & 13 & 92 & 10 & 92 & 18 & 88 & 23 \\
\hline \multicolumn{9}{|l|}{ All participants } \\
\hline $\mathrm{BMI} \geq 25 \mathrm{~kg} \mathrm{~m}^{-2}$ & 86 & 42 & 83 & 40 & 76 & 56 & 75 & 56 \\
\hline$W C \geq 80 \mathrm{~cm}$ & 91 & 47 & 94 & 47 & 83 & 51 & 83 & 66 \\
\hline WHR $\geq 0.8$ & 87 & 43 & 89 & 39 & 76 & 56 & 74 & 59 \\
\hline $\mathrm{WHtR} \geq 0.5$ & 89 & 36 & 90 & 33 & 81 & 51 & 78 & 58 \\
\hline
\end{tabular}

BMI - body mass index; WC - waist circumference; WHR - waist-to-hip ratio; WHtR - waist-to-height ratio.

*Hypertension was defined as systolic blood pressure $\geq 140 \mathrm{mmHg}$ or diastolic blood pressure $\geq 90 \mathrm{mmHg}$ or current use of antihypertensive medication; diabetes was defined as fasting plasma glucose $\geq 126 \mathrm{mg} \mathrm{dl}^{-1}$ or 2-hour plasma glucose $\geq 200 \mathrm{mg} \mathrm{dl}^{-1}$; dyslipidaemia was considered as having total cholesterol $\geq 240 \mathrm{mg} \mathrm{dl}^{-1}$ or triglycerides $\geq 200 \mathrm{mg} \mathrm{dl}^{-1}$ or high-density lipoprotein cholesterol $<40 \mathrm{mg} \mathrm{dl}^{-1}$ or low-density lipoprotein cholesterol $\geq 160 \mathrm{mg} \mathrm{dl}^{-1}$.

† Risk factors include hypertension, diabetes and dyslipidaemia.

Table 5 Comparison of anthropometric measures for predicting 'at least one risk factor' in Tehranian women; Tehran Lipid and Glucose Study*

\begin{tabular}{|c|c|c|c|c|c|c|}
\hline \multirow[b]{2}{*}{$\begin{array}{l}P \text {-value (McNemar } \\
\text { chi-square statistic) }\end{array}$} & \multicolumn{4}{|c|}{ Percentage of individuals identified with risk factor by: } & \multicolumn{2}{|c|}{$\begin{array}{l}\text { Measures } \\
\text { compared }\end{array}$} \\
\hline & $\begin{array}{l}\text { Second measure } \\
\text { only }(\%) \dagger\end{array}$ & $\begin{array}{l}\text { First measure } \\
\text { only }(\%) \ddagger\end{array}$ & $\begin{array}{c}\text { Neither measure } \\
(\%) \S\end{array}$ & $\begin{array}{c}\text { Both measures } \\
\text { (\%) } 9\end{array}$ & Second & First \\
\hline 0.001 & 11 & 5 & 13 & 71 & $w C \|$ & BMIII \\
\hline 0.54 & 12 & 13 & 12 & 63 & WHR\| & BMI \\
\hline 0.21 & 8 & 6 & 13 & 73 & WHtR\| & BMI \\
\hline 0.001 & 4 & 9 & 15 & 72 & WHR & WC \\
\hline 0.01 & 1 & 4 & 15 & 80 & WHtR & WC \\
\hline 0.001 & 10 & 3 & 14 & 73 & WHtR & WHR \\
\hline
\end{tabular}

WC - waist circumference; WHR - waist-to-hip ratio; WHtR - waist-to-height ratio; BMI - body mass index.

${ }^{*}$ Risk factors include hypertension, diabetes and dyslipidaemia.

† Cell values represent the percentage of individuals who were accurately identified by the second measure only.

$\ddagger$ Cell values represent the percentage of individuals who were accurately identified by the first measure only.

$\S$ Cell values represent the percentage of individuals who were not accurately identified by either measure.

I Cell values represent the percentage of individuals who were accurately identified by both measures.

II Cut-off points of WC, BMI, WHR and WHtR were considered as $80 \mathrm{~cm}, 25 \mathrm{~kg} \mathrm{~m}^{-2}, 0.8$ and 0.5 , respectively.

and space needed to measure height and weight. By requiring a single measurement opposed to the ratio of two measures, it is less susceptible to measurement and calculation errors. There are a number of problems inherent in the use of a ratio indicator, including statistical limitations $^{44}$ and biological interpretation ${ }^{19}$. WC relates closely to intra-abdominal fat mass ${ }^{45}$ and changes in WC reflect changes in cardiovascular risk factors? ${ }^{9}$. Previous studies found large WC to be strongly associated with risk factors for the insulin resistance syndrome ${ }^{46}$ and breast cancer in women ${ }^{47}$, suggesting that WC may have wider value as a measure of total health risks.

There are several points that should be considered when examining the results of this study. The site of waist measurement in this study was the point of noticeable waist narrowing, which may have resulted in lower WC values than might be obtained using other common sites of measurement. While the WHO Expert Committee ${ }^{7}$ on Physical Status recommends measurement midway between the lower rib and the iliac crest, the NHANES III guidelines ${ }^{48}$ prescribe use of a point just above the right ileum, and the recommendation of the North American Association for the Study of Obesity and the National Heart, Lung, and Blood Institute ${ }^{49}$ is to use the right iliac crest. The lack of standard measurement for WC is unfortunate, and makes comparison with other studies difficult. It is believed that the use of narrowest waist measurement offers greater ease of acceptance and 
interpretation by the public and may facilitate selfmeasurement in addition to clinical use. On the other hand, it should be kept in mind that the optimal values of WC are age-dependent and no single cut-off point of WC is optimal for all ages and for different cardiovascular risk factors. For practical reasons, the value of $90 \mathrm{~cm}$ for men and $80 \mathrm{~cm}$ for women may be the best measures to use for the population at large and in a clinical setting ${ }^{16}$. The principal limitation of this study was the use of crosssectional data to compare the ability of anthropometric indices to predict CVD risk factors. Future studies using longitudinal data will provide stronger evidence on this evaluation. Sensitivity and specificity, although not affected by the prevalence of CVD risk factors, are influenced by parameters used in the definitions of the CVD risk factors (such as dyslipidaemia). Some accuracy may be lost in the determination of McNemar's chi-square statistic for comparison of the predictive ability of the various anthropometric measures. Unfortunately, data on income have not been gathered in the TLGS. This could confound the relationships reported. Chronic diseases are heterogeneous and multifactorial and, besides anthropometric measurements, other factors such as hereditary and lifestyle-related factors must be considered. On the other hand, CVD risk factors are interrelated and this could confound the relationship of anthropometry and these risk factors. The strength of this study is using a populationrepresentative sample of our country to compare the predictive ability of WC, WHR, WHtR and BMI. This enhances the validity of our findings. However, no data are available regarding Iranians who have emigrated, and it is recommended to conduct similar studies on Iranians who have emigrated. Regarding Iranian men, we showed previously that WHR was a better indicator of CVD risk factors $^{50}$. This gender discrepancy may be explained by the fact that women have a higher percentage of body fat than men at a given $W^{51}$. Despite these discrepancies the overall message remains similar: that preferential abdominal fat accumulation is detrimental to human health.

Given the aforementioned limitations, it is concluded that, compared with BMI, WHR and WHtR, WC may be a better indicator of cardiovascular risk factors in Tehranian adult women. This finding underscores the inclusion of the measurement of WC in clinical examinations. Although this study was performed on a sample of Asian women for whom there is a scarcity of reports, it should be considered that the characteristics of this sample may not be comparable to those of other populations of Asian women. Thus extrapolation of the findings should be done with extreme caution.

\section{Acknowledgements}

Funding support: This study was supported by grant no. 121 from the National Research Council of the Islamic Republic of Iran, and by the combined support of the
National Research Council of the Islamic Republic of Iran and Endocrine Research Center of Shaheed Beheshti University of Medical Sciences.

Conflict of interest: None of the authors had any personal or financial conflicts of interest.

Contributors: A.E. and P.M. designed the study, collected and analysed data, and wrote the manuscript. F.A. supervised the study.

Acknowledgements: We thank the participants of the Tehran Lipid and Glucose Study for their enthusiastic support and the staff of the Endocrine Research Center, TLGS unit, for their valuable help in conducting this study.

\section{References}

1 Mokdad AH, Serdula MK, Dietz WH, Bowman BA, Marks JS, Koplan JP. The continuing epidemic of obesity in the United States. Journal of American Medical Association 2000; 284: 1650-1.

2 Kuczmarski RJ, Flegal KM, Campbell SM, Johnson CL. Increasing prevalence of overweight among US adults. The National Health and Nutrition Examination Surveys, 1960 to 1991. Journal of American Medical Association 1994; 272 : 205-11.

3 deOnis M, Blossner M. Prevalence and trends of overweight among preschool children in developing countries. American Journal of Clinical Nutrition 2000; 72: 1032-9.

4 World Health Organization. Obesity epidemic puts millions at risk from related diseases. Press release WHO/46, 1997 [online]. Available at http//:www.who.int/inf-prp 1997/en/pr97-46.html.

5 Pishdad GR. Overweight and obesity in adults aged $20-74$ in southern Iran. International Journal of Obesity and Related Metabolic Disorders 1996; 20: 963-5.

6 Azizi F, Esmaillzadeh A, Mirmiran P. Obesity and cardiovascular risk factors in Tehranian adults: a population-based cross-sectional study. Eastern Mediterranean Health Journal 2004; 10: 887-97.

7 World Health Organization (WHO). Obesity: Preventing and Managing the Global Epidemic. Report of a WHO Consultation on Obesity. WHO/NUT/NCD/98.1. Geneva: WHO, 1997.

8 Stevens J, Cai J, Pamuk ER, Williamson DF, Thun MJ, Wood JL. The effect of age on the association between body mass index and mortality. New England Journal of Medicine 1998; 338: $1-7$.

9 Wei M, Gaskill SP, Haffner SM, Stern MP. Waist circumference as the best predictor of non-insulin dependent diabetes mellitus compared to BMI, WHR over other anthropometric measurements in Mexican Americans: a 7-year prospective study. Obesity Research 1997; 5: 16-23.

10 Folsom AR, Kaye SA, Sellers TA, Hong CP, Cerhan JR, Potter $\mathrm{JD}$, et al. Body fat distribution and 5-year risk of death in old women. Journal of American Medical Association 1993; 269: $483-7$.

11 Pi-Sunyer FX. Obesity: criteria and classification. Proceedings of Nutrition Society 2000; 59: 505-9.

12 Hayashi T, Boyko EJ, Leonetti DL, McNeely MJ, NewellMorris L, Kahn SE, et al. Visceral adiposity is an independent predictor of incident hypertension in Japanese Americans. Annals of Internal Medicine 2004; 140: 992-1000.

13 Cox BD, Whichelow MJ, Prevost AT. The development of cardiovascular disease in relation to anthropometric indices and hypertension in British adults. International Journal of Obesity and Related Metabolic Disorders 1998; 22: $966-73$. 
14 Pouliot MC, Despres JP, Lemieux S, Moorjani S, Bouchard C, Tremblay A, et al. Waist circumference and abdominal sagittal diameter: best simple anthropometric indexes of abdominal visceral adipose tissue accumulation and related cardiovascular risk in men and women. American Journal of Cardiology 1994; 73: 460-8.

15 Ledoux M, Lambert J, Reeder BA, Despres JP. A comparative analysis of weight to height and waist to hip circumference indices as indicators of the presence of cardiovascular disease risk factors. Canadian Heart Health Surveys Research Group. Canadian Medical Association Journal 1997; 157: S32-8.

16 Dobbelsteyn CJ, Joffres MR, MacLean DR, Flowerdew G and the Canadian Heart Surveys Research Group. A comparative evaluation of waist circumference, waist-to-hip ratio and body mass index as indicators of cardiovascular risk factors: The Canadian Heart Health Surveys. International Journal of Obesity and Related Metabolic Disorders 2001; 25: 652-61.

17 Seidell JC, Cigolini M, Charzewska J, Ellsingen BM, di-Biase G. Fat distribution in European women: a comparison of anthropometric measurements in relation to cardiovascular risk factors. International Journal of Epidemiology 1990; 19: 303-8.

18 Woo J, Ho SC, Yu AL, Sham A. Is waist circumference a useful measure in predicting health outcomes in the elderly? International Journal of Obesity and Related Metabolic Disorders 2002; 26: 1349-55.

19 Molarius A, Seidell JC. Selection of anthropometric indicators for classification of abdominal fatness - a critical review. International Journal of Obesity and Related Metabolic Disorders 1998; 22: 719-27.

20 Gallagher D, Visser M, Sepulveda D, Pierson RN, Harris T, Heymsfield SB. How useful is body mass index for comparison of body fatness across age, sex and ethnic groups? American Journal of Epidemiology 1996; 143: $228-39$.

21 Azizi F, Rahmani M, Emami H, Majid M. Tehran Lipid and Glucose Study: rationale and design. CVD Prevention 2000; 3: $242-7$.

22 Azizi F, Emami H, Salehi P, Ghanbarian A, Mirmiran P, Mirbolooki M, et al. Cardiovascular risk factors in the elderly: the Tehran Lipid and Glucose Study. Journal of Cardiovascular Risk 2003; 10: 65-73.

23 Mirmiran P, Mohammadi F, Allahverdian S, Azizi F Estimation of energy requirements for adults: Tehran Lipid and Glucose Study. International Journal for Vitamin and Nutrition Research 2003; 73: 193-200.

24 Mirmiran P, Mohammadi F, Allahverdian S, Azizi F. Association of educational level and marital status with dietary intake and cardiovascular risk factors in Tehranian adults: Tehran Lipid and Glucose Study. Nutrition Research 2002; 22: 1365-75.

25 Wang J, Thornton JC, Bari S, Williamson B, Gallagher D, Heymsfield SB, et al. Comparisons of waist circumferences measured at 4 sites. American Journal of Clinical Nutrition 2003; 77: 379-84

26 Friedewald WT, Levy RI, Fredrickson DS. Estimation of the concentration of low-density lipoprotein cholesterol in plasma, without use of the preparative ultracentrifuge. Clinical Chemistry 1972; 18: 499-502.

27 National Cholesterol Education Program (NCEP) Expert Panel on Detection, Evaluation, and Treatment of High Blood Cholesterol in Adults (Adult Treatment Panel III). Third report of the National Cholesterol Education Program (NCEP) Expert Panel on Detection, Evaluation, and Treatment of High Blood Cholesterol in Adults. Circulation 2002; 106: 3143-421

28 Joint National Committee on Prevention, Detection, Evaluation and Treatment of High Blood Pressure. The sixth report of the Joint National Committee on Prevention, Detection, Evaluation and Treatment of High Blood Pressure. Archives of Internal Medicine 1997; 157: 2413-46

29 Expert Committee on the Diagnosis and Classification of Diabetes Mellitus. Report of the Expert Committee on the Diagnosis and Classification of Diabetes Mellitus. Diabetes Care 1997; 20: 1183-97

30 Ross R, Shaw KD, Martel Y, de Guise J, Avruch L. Adipose tissue distribution measured by magnetic resonance imaging in obese women. American Journal of Clinical Nutrition 1993; 67: 470-5.

31 Larsson B, Svardsudd K, Welin L, Wilhelmsen L, Bjorntorp P, Tibblin G. Abdominal adipose tissue distribution, obesity, and risk of cardiovascular disease and death: 13 year follow up of participants in the study of men born in 1913. British Medical Journal 1984; 288: 1401-4.

32 Schmidt MI, Watson RL, Duncan BB, Metcalf P, Brancati FL, Sharrett AR, et al. Clustering of dyslipidemia, hyperuricemia, diabetes, and hypertension and its association with fasting insulin and central and overall obesity in a general population: Atherosclerosis Risk in Communities Study Investigators. Metabolism 1996; 45: 699-706.

33 Zhu S, Wang Z, Heshka S, Heo M, Faith MS, Heymsfield SB. Waist circumference and obesity-associated risk factors among whites in the third National Health and Nutrition Examination Survey: clinical action thresholds. American Journal of Clinical Nutrition 2002; 76: 743-9.

34 Hwu CM, Fuh JL, Hsiao CF, Wang SJ, Lu SR, Wei MC, et al. Waist circumference predicts metabolic cardiovascular risk in postmenopausal Chinese women. Menopause 2003; 10: 73-80.

35 Pelt RE, Evans EM, Schechtman KB, Ehsani AA, Kohrt WM. Waist circumference vs body mass index for prediction of disease risk in postmenopausal women. International Journal of Obesity and Related Metabolic Disorders 2001; 25: $1183-8$.

36 Foucan L, Hanley J, Deloumeaux J, Suissa S. Body mass index and waist circumference as screening tools for cardiovascular risk factors in Guadeloupean women. Journal of Clinical Epidemiology 2002; 55: 990-6.

37 Lin WY, Lee LT, Chen CY, Lo H, Hsia HH, Liu IL, et al. Optimal cut-off values for obesity: using simple anthropometric indices to predict cardiovascular risk factors in Taiwan. International Journal of Obesity and Related Metabolic Disorders 2002; 26: 1232-8.

38 Hsieh SD, Yoshinaga H. Waist/height ratio as a simple and useful predictor of coronary heart disease risk factors in women. Internal Medicine 1995; 34: 1147-52.

39 Ito H, Nakasuga K, Ohshima A, Maruyama T, Kaji Y, Harada $\mathrm{M}$, et al. Detection of cardiovascular risk factors by indices of obesity obtained from anthropometry and dual-energy X-ray absorptiometry in Japanese individuals. International Journal of Obesity and Related Metabolic Disorders 2003; 27: $232-7$.

40 Kortelainen ML, Sarkioja T. Coronary atherosclerosis and myocardial hypertrophy in relation to body fat distribution in healthy women: an autopsy study on 33 violent deaths. International Journal of Obesity and Related Metabolic Disorders 1997; 21: 43-9.

41 Shetterly SM, Marshall JA, Baxter J, Hamman RF. Waist-hip ratio measurement location influences associations with measures of glucose and lipid metabolism: The San Luis Valley Diabetes Study. Annals of Epidemiology 1993; 3: 295-9.

42 Lear SA, Chen MM, Frohlich JJ, Birmingham CL. The relationship between waist circumference and metabolic risk factors: cohorts of European and Chinese descent. Metabolism 2002; 51: 1427-32.

43 Daniel M, Marion SA, Sheps SB, Hertzman C, Gamble D. Variation by body mass index and age in waist-to-hip ratio 
associations with glycemic status in an aboriginal population at risk for type 2 diabetes in British Columbia, Canada. American Journal of Clinical Nutrition 1999; 69: 455-60.

44 Allison DB, Paultre F, Goran MI, Poehlman ET, Heymsfield $\mathrm{SB}$. Statistical considerations regarding the use of ratios to adjust data. International Journal of Obesity and Related Metabolic Disorders 1995; 19: 644-52.

45 Derpres JP. The insulin resistance-dyslipidemic syndrome of visceral obesity: effect on patients' risk. Obesity Research 1998; 6: 85-175.

46 Edwards KL, Austin MA, Newman B, Mayer E, Krauss RM, Selby JV. Multivariate analysis of the insulin resistance syndrome in women. Arteriosclerosis and Thrombosis 1994; 14: $1940-5$.

47 den Tonkelaar I, Seidell JC, Collette HJ. Body fat distribution in relation to breast cancer in women participating in the DOM-project. Breast Cancer Research and Treatment 1995; 34: 55-61.
48 Chumlea NC, Kuczmarski RJ. Using a bony landmark to measure waist circumference. Journal of the American Dietetic Association 1995; 95: 12.

49 National Heart, Lung, and Blood Institute. Clinical Guidelines on the Identification, Evaluation and Treatment of Overweight and Obesity in Adults - The Evidence Report. National Institutes of Health. Obesity Research 1998; 6: 51S209 S

50 Esmaillzadeh A, Mirmiran P, Azizi F. Waist-to-hip ratio is a better screening measure for cardiovascular risk factors compared to other anthropometric indicators in Tehranian adult men. International Journal of Obesity and Related Metabolic Disorders 2004; 28: 1325-32.

51 Lear SA, Chen MM, Birmingham CL, Frohlich JJ. The relationship between simple anthropometric indices and C-reactive protein: ethnic and gender differences. Metabolism 2003; 52: 1542-6. 